\title{
An "enactive" approach to integrative and comparative biology: Thoughts on the table
}

\author{
ADRIAN G. PALACIOS ${ }^{1}$ and FRANCISCO BOZINOVIC ${ }^{2}$ \\ ${ }^{1}$ Departamento de Fisiología, Facultad de Ciencias y Centro de Neurociencia de Valparaíso (CNV), \\ Universidad de Valparaíso, Chile. \\ ${ }^{2}$ Centro de Estudios Avanzados en Ecología \& Biodiversidad, Departamento de Ecología, Facultad de \\ Ciencias Biológicas, Pontificia Universidad Católica de Chile, Santiago 6513677, Chile
}

\begin{abstract}
We discuss the concept of Enaction as originally proposed by Varela. We attempt to exemplify through two specific topics, sensory ecology and behavior, as well as physiological and behavioral ecology, on which the enactive approach is based. We argue that sensory physiology allows us to explore the biological and cognitive meaning of animal 'private' sensory channels, beyond the scope of our own sensory capacity. Furthermore, after analyzing the interplay between factors that may impose limits upon an animal's use of time and energy, we call for a program of research in integrative and comparative biology that simultaneously considers evolutionary ecology (including physiological and behavioral ecology) and neurobiology (including cognitive mechanisms as well structural design). We believe that this approach represents a shift in scientific attitude among biologists concerning the place of biological and ecological topics in studies of integrative and comparative biology and biological diversity and vice versa.
\end{abstract}

\section{INTRODUCTION}

"Perception consists in perceptually guided action..." “...we must see the organism and environment as bound together in reciprocal specification and selection..." "Cognitive structures emerge from the recurrent sensorimotor patterns that enable action to be perceptually guided."

Varela et al. 1991

"Cognitive ecology focuses on the effects of information processing and decisionmaking on animal fitness. To that end, cognitive ecology employs formal evolutionary and ecological theory to address ultimate questions about the optimal design of, constraints on, and function of cognitive traits..".

Dukas, 1998
Levels of biological organization provide one of the central themes around which biologists attempt to understand biological diversity, from molecules to communities (Kooijman 2000). Mechanistic explanations for biodiversity link adjacent levels in the biological hierarchy. We believe that an understanding of the processes underlying biological patterns can be better achieved with an integration of biological disciplines and associated hierarchies, including molecular biology, physiology, ecology, and evolution. Francisco Varela challenged classical concepts of the biological organization of living beings. We discuss here the concept of 'Enaction' as originally proposed by Varela (1979) and Varela et al., (1991) in view of recent developments in cognitive ecology as well as in physiological and behavioral ecology. Modern terminology needs to be integrative and spans the interface among evolutionary biology, ecology, behavior, morphology,

Corresponding Author: Adrián G. Palacios. Centro de Neurociencias de Valparaíso (CNV). Universidad de Valparaíso. Av. Gran Bretaña 1111, Valparaíso, Chile.

Telephone: (56-32) 508048 - Fax: (56-32) 283320 - e-mail: adrian.palacios@uv.cl 
biochemistry, and physiology. Although scientists of all these areas have made important contributions to the study of biological principles, some physiologists complain that ecologists do not understand the basic mechanisms involved in the physiological integration of animals and do not use important physiological concepts and methods in their research or in the formulation of their hypotheses. Similarly, ecologists complain that physiologists have rarely addressed their research with modern theoretical and methodological approaches of evolutionary ecology.

We agree with Varela's enactive approach, which states that to explain behavior we must incorporate the study of 'coupling' or interactions between organism and environment, which represents a shift in attitude concerning the place of physiology, neurobiology and behavior in studies of evolutionary ecology and vice versa. Behaviorists need to be aware that animals experience the world through a historical set of 'structural coupling' with the environment. Dukas (1998) recently joined the discussion and interestingly tackled the problem of biological integration with the foundation for a field named 'Cognitive Ecology.' As previously occurred in the field of physiological and evolutionary ecology, Cognitive Ecology integrates theory and observations from evolutionary ecology and neurobiology, primarily cognitive science, in order to understand the effect of animal interaction with their habitat has on their cognitive systems and those systems (function and structure) restrict behavior within an ecological and evolutionary framework. In this context, Varela's enaction proposal views "the organism and environment are bound together in reciprocal specification and selection" (Varela et al. 1991 Chapter 8) and requires that any integral approach needs to incorporate the organism and the environment into a common framework wherein they become dynamically dependent upon each other. In what follows we attempt to exemplify through specific topics where the enactive approach can look for foundation.

\section{SENSORY ECOLOGY \& BEHAVIOR}

The ultimate design in a sensory system results from a co-determination -after millions of years of trial and error- between organism and environment. Thompson et al. (1992) proposed an enactive view to understanding sensory systems, noting that explanations derived from neurophysiology, computation or philosophy alone are unsatisfactory. The sensory experience of the world is built in the course of animal action "through a network consisting of multiple levels of interconnected, sensorimotor subnetworks" (Varela et al. 1991) in a brain that supports the behavioral response (e.g. food selection, intra- and/or inter-specific recognition). A series of classical studies on motor- or sensorydeprived experiences supports Varela's position. In a sensorimotor task, a group of kittens actively explore the environment and thus their brains develop neuronal selectivity to orientation, movement and depth. However, a similar but passive group does not develop neuronal selectivity and has low visual capabilities. Along with similar results on bird song, social or sexual imprinting and visual binocularity, neurobiologists coined the concept of 'critical period' to refer to the postnatal period of brain maturation that is sensitve to the sensorimotor experience of the environment. It would be interesting to introduce the concept of critical period into the enaction research program.

Francisco Varela et al. (1991) liked to refer to the co-evolution between ultraviolet (UV) sensitivity in bees and flowers? reflecting UV light as an example of structural coupling. Although this example of co-evolution is rather classic, it is clearly too weak to give rise to the specific mechanisms that are under co-evolution (e.g. the whole eye, or a particular class of UV sensitive opsin or a reflecting pigment in flowers). To that respect, it is relevant to consider lessons from Natural History. Interested on how colors and their receiver influence each other, Lars Chittka (1997) points out that UV sensitivity was already present in insect ancestors 570 million years ago, preceding colors in flowers 
(angiosperms) by 400 millions years. A key factor to include in the enaction program (or in any study interested in coevolution) would thus be a case-specific description of the biological structures that authors are referring to.

In our search for examples of "structural coupling,' we began to study the visual system of Octodon degus (Rodentia: Octodontidae), a diurnal-crepuscular rodent, and the chromatic characteristic of the degus environment. The degus retina has a high percentage of cones, and measuring the spectral sensitivity of the eye with electroretinogram (ERG) shows the presence of a mid- and short-UV wavelength sensitive mechanism (Chavez et al., 2003). What is it in the degus environment that reflects UV that can make sense to the eye UV sensitivity? Degus body and microhabitat objects provide some clues. The dorsal body and lack of UV reflectance is inconspicuous compared to its natural background. Instead, the ventral body reflects up to $20 \%$ UV (Chavez et al., 2003), suggesting a potential signal for social communication during 'alert calls' or 'vigilance' behaviors, where $O$. degus expose their ventral bodies to their cospecifics by standing on their hind limbs (Vazquez, 1997). Voles (rodent: Microtus agresti) mark runways with urine and fecal scents that are UV-visible by kestrels (Falco tinnunculus). Furthermore, kestrels use these marks to track the presence of voles from the air, scanning large areas in a short time (Koivula et al. 1999). We measured $O$. degus urine and found that it reflected preferentially in the UV and up to $40 \%$ of incident light. We suggest that the scent of rodent urine as a 'visual pheromone,' a possible mechanism that co-evolves with the rodent UV sensitivity (Chavez et al. 2003).

Rodents (rats, gerbils, mice, hamsters) show higher UV sensitivity in behavioral tasks when compared to an ERG method. This observation suggests that the 'cognitive' aspects associated with UV signals in behavioral tasks are more salient than the sum of UV receptor responses in the ERG (Jacobs et al., 1991; Jacobs \& Deegan, 1994, Glosmann \& Ahnelt, 2002).
Along this line, wavelength spectral sensitivity in the rudd (Scardinuis erythropthamus) also depends on behavioral tasks. Rudd develop an escape behavior in response to moving objects and its maximal spectral sensitivity $\left(\lambda_{\max }\right)$ response is in the red $(600 \mathrm{~nm})$. However, when the rudd learns to discriminate between two color spots to obtain food, their $\lambda_{\text {max }}$ range from $U V$ to red (Muntz, 1975; Neumeyer, 1992).

High sensitivity in low ambient light potentially associated with color vision has been described in fish (Roessel et al., 1997). Danio aequipinnatus night sensitivity has a broader ERG band in the red than expected from a single-rod response. We explored the possibility that low vs. high sensitivity cones are present in the D. aequipinnatus retina. We measured photocurrents from isolated cones in response to different wavelengths, and we distinguished four different classes with $\lambda_{\text {max }}$ in the UV, blue, green, and red (Palacios et al., 1996). Each class presented cones with high sensitivity close to rods (Palacios et al., 2000). On the hand, dichromatic vision based on rods and red cones has been described in goldfish (Power \& Easter, 1978). This result opens the fascinating possibility that animals experience color vision under moonlight.

The natural light distribution -intensity and hue- over days, hours, minutes and the visual system capacities should be considered in a dynamic relationship. The dimensionality of a color space depends on the background intensity level of the ambient. In high illumination the goldfish is tetrachromatic. However, at mid-level illumination, it becomes trichromatic (Neumeyer 1992).

Those examples of context coupling dependence between sensory biology and environment are important to consider in the study of the biological roots of 'enaction.' Sensory physiology offers the possibility of exploring the biological and cognitive meaning of 'private' sensory channels in animals, apart from the scope of our own sensory capacity. Further, studies challenging the enaction program will need to consider how specific behaviors 
and environment are dynamically coupled, in the sense introduced by Francisco Varela.

INTEGRATING PHYSIOLOGICAL AND BEHAVIORAL ECOLOGY

A major goal in behavioral and physiological ecology is to understand the interaction between factors that may impose limits on an animal's use of time and energy. An example that integrates physiology, behavior and environment is foraging. In the next section we attempt to demonstrate that analysis of foraging behavior would be greatly benefited from the integration of neurobiological (cognitive), physiological, evolutionary, and ecological research.

Hummingbirds are among the smallest endothermic vertebrates and have extremely high mass-specific metabolic rates (LópezCalleja \& Bozinovic, 2003). Energy expenditure of hummingbirds during foraging reaches the upper limits recorded for vertebrates (Suarez 1998). Furthermore, hummingbirds often face marked fluctuations in environmental conditions. This, along with their high energy requirements, determine that hummingbirds present a tightly-coupled energy balance and show rapid behavioral and physiological responses to changes in environmental conditions and food availability. Theoretically, when an animal minimizes the amount of time spent to meet its energy/ nutritional requirements or maximizes the amount of energy obtained, it is considered to be maximizing its fitness. Fernández et al. (2002), however, demonstrated that, depending on the interaction between environmental and energetic constraints, the Sephanoides sephaniodes (Trochilidae) hummingbird decreases its net energy intake by choosing an energy-saving behavior. This associative learning behavior allows hummingbirds great flexibility in managing their energy reserves.

Another example is that of Octodon degus. As emphasized above, all organisms need energy, and many of their spatial and temporal activities focus on how to obtain, process, and conserve it. Kenagy et al. (2002a, b) presented an analysis of behavioral the flexibility of $O$. degus, in integrative response to the temporal (daily, seasonal), spatial, and thermal heterogeneity of its environment. The authors quantified activity and foraging behavior and thermal conditions in a population in an extremely open habitat in the seasonally hot and arid 'matorral' of central Chile. In addition, Bacigalupe et al. (2003) manipulated food availability and compared open and shaded study plots to determine the influence of thermal conditions on above-ground activity. In extremely open areas, flexibility in the timing of surface activity allows the degus to maintain thermal homeostasis and energy balance throughout the year. Degus shift the times of daily onset and termination of activity as well as the number of major episodes (unimodal or bimodal) over the course of the year. Their surface activity occurs under a much narrower range or 'window' of thermal conditions than those that occur over the entire broad range of the day and year. When shrubs are available, degus display a bimodal pattern of daily activity during relatively warmer thermal of autumn, whereas activity was unimodal during cooler winter conditions.

Classic and theoretical frameworks dealing with foraging behavior pose that behaviors depend on the ecological context in which foraging takes place (Stephens \& Krebs, 1986). Nevertheless, as exemplified by hummingbirds and degus, the interaction of physiological capabilities, in combination with cognitive skills and the availability and properties of food resources can also have important, albeit relatively unstudied effects, on foraging mode.

Based on the examples above, we are calling for a program of research in integrative and comparative biology that simultaneously considers evolutionary ecology (including physiological and behavioral ecology) and neurobiology (including cognitive mechanisms as well as structural design). Again, from our perspective, this approach represents a shift in scientific attitude on behalf of biologists concerning the place of biological and ecological topics in studies of integrative 
and comparative biology and biological diversity and vice versa.

\section{ACKNOWLEDGEMENTS}

This article is dedicated to the memory of our teacher and friend Francisco 'Pancho' Varela, from whom we received our vision of integrative and comparative biology and our passion for science. Supported by FONDAP grant \#1501-001 (Program1) (FB), Fondecyt \#1000396, and Mideplan ICM \# P99-037-F (AGP). We thank F. Jaksic and J. Bacigalupo for their critical commentary.

\section{REFERENCES}

BACIGALUPE LD, REZENDE EL, KENAGY GJ, BOZINOVIC F (2003) Variability in activity and space use by degus: a trade-off between thermal conditions and food availability? J Mammal 84: 000000 (In press)

CHAVEZ A, BOZINOVIC F, PEICHL L, PALACIOS AG (2003) Reflectance in the genus Octodon (Rodentia): Implications for visual ecology retinal spectral sensitivity, fur coloration and urine. Investigative Ophthalmology Visual Science (In press)

CHITTKA L (1997) Bee color is optimal for coding flower color, but flower colors are not optimal for being coded- why? Israel J Plant Sci 45:115-127

DUKAS R (1998) Cognitive ecology. The evolutionary ecology of information processing and decision making. Chicago: University of Chicago Press

FERNÁNDEZ MAJ, LÓPEZ-CALLEJA MV, BOZINOVIC F (2002) Interplay between foraging energetic and thermoregulatory costs in hummingbirds. J Zoo London 258: 319-326

GLOSMANN M, AHNELT PKA (2002) Mouse-like retinal cone phenotype in the Syrian hamster: $S$ opsin coexpressed with $M$ opsin in a common cone photoreceptor. Brain Res 929:139-46

JACOBS GH, NEITZ J, DEEGAN JF (1991) Retinal receptors in rodents maximally sensitive to ultraviolet light. Nature 353:655-656

JACOBS GH, DEEGAN JF (1994) Spectral sensitivity, photo pigments, and color vision in the guinea pig (Cavia porcellus). Behav Neurosci 108:993-1004
KENAGY GJ, VASQUEZ RA, NESPOLO RF, BOZINOVIC F (2002a) A time-energy analysis of daytime surface activity in degus, Octodon degus. Revista Chilena de Historia Natural 75: 149-156

KENAGY GJ, NESPOLO RF, VASQUEZ RA, BOZINOVIC F (2002b) Daily and seasonal limits of time and temperature on surface activity of degus. Rev Chilena de Historia Natural 75: 567-581

KOIVULA M, KOSKELA E, VIITALA J (1999) Sex and age-specific differences in ultraviolet reflectance of scent marks of bank voles (Clethrionomys glareolus). J Comp Physiol A;185:561-564

KOOIJMAN K (2000) Dynamic energy and mass budgets in biological systems. 2nd ed, Cambridge, MA: Cambridge University Press

LOPEZ-CALLEJA MV, BOZINOVIC F (2003) Dynamic energy and time budget in hummingbirds: a study in Sephanoides sephaniodes. Comparative Biochemistry \& Physiology 00:000-000. In press

MUNTZ WRA (1975) Behavioral studies of vision in a fish and possible relationships to the environment. In: ALI MA (ed). Vision in Fish. New York: Plenum

NEUMEYER C (1992) Tetrachromatic color vision in goldfish: Evidence from color mixture experiments. J Comp Physiol A, 171:639-649

PALACIOS AG, GOLDSMITH TH, BERNARD G (1996) Sensitivity of cones from a cyprinid fish (Danio aequipinnatus) to ultraviolet and visible light. Vis Neurosci 13:411-421

ROESSEL VAN P, PALACIOS AG, GOLDSMITH TH (1997) Activity of long-wavelength cones under scotopic conditions in the cyprinid fish Danio aequipinnatus. J Comp Physiol A 181:493-500

PALACIOS AG, VAN ROESSELL P, GOLDSMITH TH (2000) Spectral and absolute sensitivity of vertebrate photoreceptors J Physiol, London 523P: 13S

POWERS MK, EASTER SS JR (1978) Wavelength discrimination by the goldfish nears absolute visual threshold. Vision Res 18 1149-1154

STEPHENS, DW, KREBS JR (1986) Foraging Theory. Princeton: Princeton University Press

SUAREZ RK (1998) Oxygen and the upper limits to animal design and performance. J Exp Biol 201: 1065-1072

THOMPSON E, PALACIOS A, VARELA F (1992) Ways of coloring: Comparative color vision as case study for cognitive science. Behav Brain Sci 15:1-74

VARELA FJ (1979) Principles of Biological Autonomy. Holland: Elsevier North

VARELA FJ, THOMPSON E, ROSCH E (1991) The Embodied Mind: Cognitive Science and Human Experience. Cambridge, MA: MIT Press VASQUEZ $\mathrm{R}$ (1997) Vigilance and social foraging in Octodon degus (Rodentia, Octodontidae) in central Chile. Rev Chil Hist Nat 70: 557-563 